\title{
Profiling nitric oxide metabolites in patients with idiopathic pulmonary arterial hypertension
}

\author{
Rui Zhang ${ }^{1,3}$, Xiao-Jian Wang ${ }^{2,3}$, Hong-Da Zhang ${ }^{1}$, Xiao-Qing Sun ${ }^{1}$, \\ Qin-Hua Zhao ${ }^{1}$, Lan Wang ${ }^{1}$, Jing He ${ }^{1}$, Xin Jiang ${ }^{2}$, Jin-Ming Liu ${ }^{1}$ and \\ Zhi-Cheng Jing ${ }^{1,2}$
}

Affiliations: 'Dept of Cardio-Pulmonary Circulation, Shanghai Pulmonary Hospital, Tongji University School of Medicine, Shanghai, China. ${ }^{2}$ State Key Laboratory of Cardiovascular Disease, FuWai Hospital, Peking Union Medical College and Chinese Academy Medical Science, Beijing, China. ${ }^{3}$ Both authors contributed equally.

Correspondence: Zhi-Cheng Jing, State Key Laboratory of Cardiovascular Disease, FuWai Hospital, Peking Union Medical College and Chinese Academy Medical Science, No. 167 Beilishi Road, Beijing 100037, China. E-mail: jingzhichengavip.163.com

ABSTRACT Intact nitric oxide (NO) signalling is critical to maintaining appropriate pulmonary vascular tone. NO bioavailability is reduced in patients with pulmonary arterial hypertension. This study aimed to examine the impact of NO plasma metabolites (NOx) relative to haemodynamic dysfunction and mortality in patients with idiopathic pulmonary arterial hypertension (IPAH).

A total of 104 consecutive adult IPAH patients who had undergone genetic counselling when first diagnosed were enrolled in this prospective study.

The median concentration of NOx $\left(\mu \mathrm{mol} \cdot \mathrm{L}^{-1}\right)$ was significantly lower in IPAH patients compared with healthy subjects, and was decreased further in 19 carriers of the bone morphogenetic protein-receptor type-2 (BMPR2) mutation compared to non-carriers. Reduced concentrations of NOx were correlated with mean pulmonary arterial pressure (mPAP), pulmonary vascular resistance (PVR) and cardiac output. Compared with higher baseline NOx concentrations, patients with a NOx concentration of $\leqslant 10 \mu \mathrm{mol} \cdot \mathrm{L}^{-1}$ had a markedly worse survival. After adjustment for clinical features, a BMPR2 mutation and haemodynamics, a lower NOx level remained an increased risk of mortality.

Patients with IPAH had lower levels of plasma NOx, which correlated inversely with mPAP, PVR and survival. Plasma NOx may be an important biomarker and prognostic indicator, suggesting that reduced NO synthesis contributes to the pathogenesis of IPAH.

@ERSpublications

Plasma NOx was significantly lower, and related to haemodynamics, mortality and BMPR2 mutation in patients with IPAH http://ow.ly/vyNO301PNyZ

Editorial comment in Eur Respir J 2016; 48:1265-1267.

This article has supplementary material available from erj.ersjournals.com

Received: Feb 012016 | Accepted after revision: June 22 2016 | First published online: Sept 222016

Support statement: The study was partly supported by the National Natural Science Foundation of China (81470245 and 81320108005), and National Natural Science Funds for Distinguished Young Scholar (81425002). Funding information for this article has been deposited with the Open Funder Registry. The sponsors had no involvement in the study's design, the data analyses, data interpretation, and writing or revision of the manuscript.

Conflict of interest: Disclosures can be found alongside this article at erj.ersjournals.com

Copyright OERS 2016 


\section{Introduction}

Although pulmonary arterial hypertension $(\mathrm{PAH})$ is a severe and life-threatening disease with still largely unknown pathogenesis, it is well accepted that one factor in the progression of PAH is an imbalance between vasodilation and vasoconstriction in pulmonary circulation [1]. Chronically impaired production of vasoactive mediators, such as nitric oxide (NO) and prostacyclin, along with prolonged over-expression of vasoconstrictors, such as endothelin-1, not only affect vascular tone but also promote vascular remodelling [2]. The pulmonary artery bed appears unreactive to vasodilators in disease evolution, vasoreactivity and remodelling.

Reduced NO bioavailability in PAH could be caused by decreased expression of endothelial NO synthase (eNOS) and inhibition of eNOS activity. Thus, patients with idiopathic PAH (IPAH) have reduced NO formation and eNOS activity [3,4]. At lower concentrations, NO serves a regulator via the activation of soluble guanylate cyclase (sGC), resulting in increased cyclic guanosine monophosphate (cGMP) levels in target cells. Therefore, NO synthesis and signalling through eNOS/NO-sGC-cGMP pathway have been proposed as a potential therapy. Some currently approved therapeutics target the NO pathway, such as phosphodiesterase type 5 inhibitors (PDE-5i) and sGC stimulators $[5,6]$.

The NO/eNOS system plays a critical homeostatic role in cardiovascular disease. Patients with IPAH have higher plasma level of asymmetric and symmetric dimethylarginine, which act as endogenous inhibitors of eNOS and have been implicated in pulmonary arterial endothelial dysfunction [3, 7]. In addition, knockout of eNOS mice spontaneously develop multiple cardiovascular disorders $[3,8]$. Moreover, NAGAYA et al. [9] have suggested that treatment with L-arginine, the substrate of eNOS, may have beneficial effects on the haemodynamics and exercise tolerance in patients with PAH. Because NO is a diatomic free radical that is extremely short-lived in biological systems, the established paradigm for NO biochemistry from production by eNOS to activation of sGC to eventual oxidation to $\mathrm{NOx}$ (nitrite $\left(\mathrm{NO} 2^{-}\right.$) plus nitrate $\left(\mathrm{NO}^{-}\right)$), may represent part of NO's affects in vivo [10]. Plasma NOx, stable NO metabolites, act as a biomarker for NO formation in vivo and a routine indirect NO measurement [11-14]. Additionally, 20\% of patients with IPAH carry a mutation for bone morphogenetic protein-receptor type-2 (BMPR2), where a loss of BMPR2 function can compromise the integrity of the endothelial barrier and contribute to endothelial dysfunction by mediating eNOS activation $[15,16]$.

Recognition of NO production and its clinical implications are needed to better understand PAH pathophysiology and to facilitate potential therapeutic strategies. Accordingly, the objective of the present study was to prospectively determine whether: 1) abnormalities of NO metabolism were related to haemodynamic dysfunction; 2) patients with BMPR2 mutation had more severely reduced NOx levels; and 3) whether plasma NOx level is a predictor of prognoses and outcomes.

\section{Patients and methods}

Subjects

A total of 104 consecutive adults patients with IPAH, aged $\geqslant 18$ years at diagnosis, and who had undergone $B M P R 2$ genetic counselling at the time of their first right heart catheterisation were prospectively enrolled in this study between January 2009 and July 2010. A total of 110 control subjects were selected from a cohort of healthy volunteers. The median age of control subjects was 40 years (range: 20-57 years), and the ratio of women to men was 3:1. IPAH was diagnosed according to standard criteria: a mean pulmonary artery pressure (mPAP) of $>25 \mathrm{mmHg}$ and pulmonary vascular resistance (PVR) of $>3$ Woods units at rest in the presence of a normal pulmonary artery wedge pressure (PAWP $<15 \mathrm{mmHg}$ ) $[5,17,18]$. Patients were excluded if this was caused by connective-tissue disease, congenital heart disease, portopulmonary hypertension, chronic pulmonary thromboembolism, pulmonary hypertension due to left heart disease, lung diseases and/or hypoxaemia. Other exclusion criteria were any potential confounding factors associated with plasma NOx production: i.e. cigarette smoking, excessive alcohol consumption, hypercholesterolaemia, hypertension or type 2 diabetes mellitus $[12,19,20]$. We also excluded participants who had received PDE-5i as a background treatment, cyclooxygenase (COX) inhibitors, including nonsteroidal anti-inflammatory medications, aspirin or COX-2 inhibitors within 14 days of blood sample collection [14, 21].

We prospectively followed-up patients for a mean $26 \pm 9$ months after enrollment and no patients had received a lung or heart-lung transplant. The major endpoint was defined as all-cause mortality. The study was conducted according to the principles of the Declaration of Helsinki and was approved by the Shanghai Pulmonary Hospital Ethics Committee. Written informed consent was obtained from all participants.

\section{Blood sampling and plasma NOx assay}

Venous blood was collected from all subjects after fasting overnight ( $>12 \mathrm{~h}$ ) to minimise the effects of foods and beverages on plasma NOx concentrations. All samples were collected directly into prepared sodium EDTA tubes containing a preservative to retard auto-oxidation. After centrifuging at $3000 \mathrm{rpm}(1750 \times g)$ at 
$4^{\circ} \mathrm{C}$ for $15 \mathrm{~min}$, the supernatants was frozen in aliquots and stored in cryotubes at $-80^{\circ} \mathrm{C}$ until assayed. All procedures were completed within $20 \mathrm{~min}$. The presence of $0.005 \%$ butylated hydroxytoluene (BHT; without glutathione) in plasma was used for anti-ex-vivo oxidation and improved stability, routinely [22, 23]. Each sample was tested within a month of collection and at least two different dilutions of the same sample (in triplicate) were analysed. To minimise the intra- and inter-assay coefficients of variation for the performance of NOx, each analyte was duplicated on three different days within one month. Plasma nitrite $\left(\mathrm{NO}^{-}\right)$and nitrate $\left(\mathrm{NO}^{-}\right)$were assessed using the Griess method after conversion of nitrate to nitrite, using a commercially available assay kit (R\&D Systems, Abingdon, UK), as previously reported [12, 13, 24].

\section{Statistical analyses}

Results are expressed as numbers, percentages and medians with corresponding 25th and 75th percentiles (interquartile range). When data were not normally distributed, a nonparametric test was used. The nonparametric two-sided Mann-Whitney U-test was used to compare baseline characteristics, haemodynamic parameters, and NOx levels. Proportions were compared with the Chi-squared test. The relations between NOx and baseline variables were assessed by Spearman rank correlation coefficients. To compare the prognostic values of NOx, brain natriuretic peptide (BNP) and selected haemodynamic parameters, receiver operating characteristic curves (ROC) were generated and the areas under the curves (AUCs) were calculated. Survival analyses were performed using the Kaplan-Meier method and were compared using the log-rank test. Cox proportional hazard regression was used for time-to-event analysis to estimate hazard ratios (HR) and 95\% confidence intervals (CI) for all-cause mortality between the two groups (NOx concentration $\leqslant 10 \mu \mathrm{mol} \cdot \mathrm{L}^{-1}$ versus $>10 \mu \mathrm{mol} \cdot \mathrm{L}^{-1}$ ). Adjustments for age and sex were included in the stepwise model with backward elimination. Other pertinent covariates thought to have clinical importance and those with p-value of $<0.20$ in the univariate analyses were considered to be confounders, including the BMPR2 mutation, MPAP, PVR, cardiac output and other clinical features and haemodynamics. A p-value less than 0.05 was considered statistically significant. All analyses were performed using the SPSS 14.0 statistical software package (Statistical Package for Social Science, Chicago, IL, USA).

\section{Results}

\section{NOx levels and characteristics of the study population}

Plasma NOx concentration was significantly decreased in all patients with IPAH compared with control subjects $\left(9.7 \mu \mathrm{mol} \cdot \mathrm{L}^{-1}\right.$; 95\% CI, 6.7-12.4 $\mu \mathrm{mol} \cdot \mathrm{L}^{-1}$ versus $29.2 \mu \mathrm{mol} \cdot \mathrm{L}^{-1}$; $95 \% \mathrm{CI}, 21.9-34.4 \mu \mathrm{mol} \cdot \mathrm{L}^{-1}$, respectively; $\mathrm{p}<0.001)$. The mean intra-coefficients of variation for all patients and controls were $24 \%$ (20\%-28\%) and 17\% (10\%-23\%), respectively. Among the 104 patients with IPAH, 19 (18.3\%) were found to be carriers of the BMPR2 mutation (BMPR2mut); the other 85 patients were wild-type BMPR2 (BMPR2wt). NOx concentration in patients with $B M P R 2$ mut was significantly decreased compared to patients in the $B M P R 2 \mathrm{wt}$ group $(B M P R 2 \mathrm{wt}, \mathrm{p}=0.007)$ (figure 1). However, there was no significant difference in the severity of World Health Organization (WHO) functional class between the two groups. The clinical characteristics are summarised in table 1. BMPR2mut patients had a younger median age at diagnosis (27 years; interquartile range 21-35 years) than those of $B M P R 2$ wt group (41 years; interquartile range $29-51$ years $)(\mathrm{p}<0.001)$. The sex ratio of females to males was 2.7:1 ( $\mathrm{n}=76$ and 28 , respectively) overall.

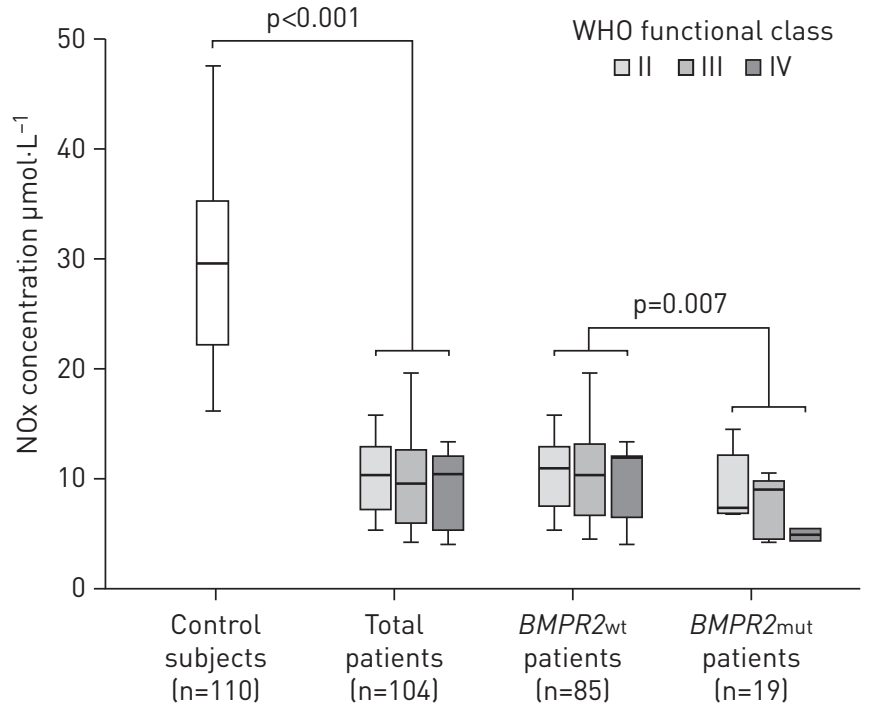

FIGURE 1 Plasma nitric oxide metabolite (NOx) concentrations in patients with idiopathic pulmonary arterial hypertension, control subjects, patients with BMPR2 mutation (BMPR2mut) and those with wild-type BMPR2 (BMPR2wt), associated with World Health Organization functional class. The line through the centre of the boxes represents the median. 


\begin{tabular}{|c|c|c|c|c|}
\hline & Total & BMPR2mut & BMPR2wt & p-value \\
\hline Patients $\mathbf{n}$ & 104 & 19 & 85 & \\
\hline Age years & $38(26-50)$ & $27(21-35)$ & $41(29-51)$ & $<0.001$ \\
\hline Female & 76 (73) & $11(58)$ & $65(76)$ & $<0.001$ \\
\hline BMI $\mathrm{kg} \cdot \mathrm{m}^{-2}$ & $22(20-24)$ & $21(19-22)$ & $22(21-25)$ & 0.23 \\
\hline WHO FC & & & & 0.06 \\
\hline Class II & 32 (31) & $5(26)$ & $27(32)$ & \\
\hline Class III & $56(54)$ & $11(58)$ & $45(53)$ & \\
\hline Class IV & $16(15)$ & $3(16)$ & 13 (15) & \\
\hline Onset to diagnosis months & $24(7-48)$ & $18(5-43)$ & $24(7-48)$ & 0.27 \\
\hline 6MWD $\mathrm{m}^{\pi}$ & $365(320-434)$ & $407(315-426)$ & $360(320-439)$ & 0.49 \\
\hline $\mathrm{BNP} \mathrm{pg} \cdot \mathrm{mL}^{-1}$ & $345(145-517)$ & 305 (144-537) & $389(155-472)$ & 0.67 \\
\hline $\mathrm{NOx} \mu \mathrm{mol} \cdot \mathrm{L}^{-1}$ & $9.7(6.7-12.4)$ & $7.3(4.6-9.8)$ & $10.7(7.1-12.8)$ & 0.007 \\
\hline \multicolumn{5}{|l|}{ Haemodynamic variables } \\
\hline Heart rate beats. $\min ^{-1}$ & $88(75-92)$ & $87(80-92)$ & $87(73-92)$ & 0.64 \\
\hline mRAP $\mathrm{mmHg}$ & $8(5-10)$ & $11(4-11)$ & $7(5-10)$ & 0.58 \\
\hline mPAP $\mathrm{mmHg}$ & $61(50-68)$ & $67(57-82)$ & $59(49-67)$ & 0.02 \\
\hline PAWP $\mathrm{mmHg}$ & $9(6-10)$ & $9(6-10)$ & $9(6-10)$ & 0.33 \\
\hline $\mathrm{CO} L \cdot \min ^{-1}$ & $3.8(3.0-5.0)$ & $3.5(2.8-5.2)$ & $4.0(3.2-4.9)$ & 0.58 \\
\hline $\mathrm{Cl} \mathrm{L} \cdot \mathrm{min}^{-1} \cdot \mathrm{m}^{-2}$ & $2.4(1.9-3.1)$ & $2.1(1.7-3.2)$ & $2.5(2.0-3.1)$ & 0.49 \\
\hline PVR Wood units & $14(9-18)$ & $17(13-22)$ & $13(8-17)$ & 0.04 \\
\hline $\mathrm{SvO}_{2} \%$ & $61(55-69)$ & $60(55-68)$ & $63(56-69)$ & 0.62 \\
\hline \multicolumn{5}{|l|}{ PAH-specific therapies $^{+}$} \\
\hline Bosentan (oral) & $15(14)$ & $4(21)$ & $11(13)$ & \\
\hline Iloprost (inhaled) & $2(2)$ & $0(0)$ & $2(2)$ & \\
\hline Sidenafil (oral) & $49(47)$ & $8(42)$ & $41(48)$ & \\
\hline Vardenafil (oral) & $17(16)$ & $2(11)$ & $15(18)$ & \\
\hline Combination therapy & $15(14)$ & $2(11)$ & $13(15)$ & \\
\hline
\end{tabular}

Data are presented as median (interquartile range) or $\mathrm{n}(\%)$, unless otherwise stated. BMI: body mass index; WHO FC: World Health Organization functional class; 6MWD: 6-min walk distance; BNP: brain natriuretic peptide; $\mathrm{NOx}$ : nitrite $\left(\mathrm{NO}_{2}^{-}\right)$plus nitrate $\left(\mathrm{NO}_{3}^{-}\right)$; mRAP: mean right atrial pressure; mPAP: mean pulmonary arterial pressure; PAWP: mean pulmonary artery wedge pressure; $\mathrm{CO}$ : cardiac output; $\mathrm{Cl}$ : cardiac index; PVR: pulmonary vascular resistance; $\mathrm{SvO}_{2}$ : mixed venous oxygen saturation; $\mathrm{PAH}$ : pulmonary arterial hypertension. \#: comparison between groups with a BMPR2mut and BMPR2wt; ": 6MWD could be successfully measured in 92 patients; $^{+}$: six $(6 \%)$ patients were enrolled in the PATENT-1(Riociguat) study.

The female/male ratio was 3.3:1 in the BMPR2wt group ( $\mathrm{n}=65$ and 20, respectively) and 1.4:1 in the $B M P R 2$ mut group ( $\mathrm{n}=11$ and 8 , respectively).

\section{Correlation of NOx levels with haemodynamic variables}

Compared with $B M P R 2$ wt patients, $B M P R 2$ mut patients had more severe haemodynamic impairment as evidenced by significantly higher mPAP and PVR (table 1). Baseline plasma NOx concentrations were negatively correlated with mPAP $(\mathrm{r}=-0.35, \mathrm{p}<0.001)$ and PVR $(\mathrm{r}=-0.36, \mathrm{p}<0.001)$, and correlated positively with cardiac output $(\mathrm{r}=0.26 ; \mathrm{p}=0.02)$ and cardiac index $(\mathrm{r}=0.23 ; \mathrm{p}=0.02)$ (figure 2). However, the baseline NOx concentration did not correlate with age, 6-min walking distance (6WMD), mean right arterial pressure or mixed venous oxygen saturation (figures S1-S4). When patients were divided into groups with mPAP of $\leqslant 50 \mathrm{mmHg}$, mPAP of $\geqslant 70 \mathrm{mmHg}$, or an intermediate group of mPAP $51-69 \mathrm{mmHg}$, there was a graded decrease in mPAP with greater NOx level (figure 3).

\section{Survival analyses}

During the follow-up period, the observed mortality rate was 25\% (26 patients) in the total IPAH population. 19 of the deaths were directly related to right ventricular failure; five were sudden deaths, but the cause of death was not able to be ascertained in two cases. All patients with IPAH were divided into two groups based on cut-off levels for NOx, calculated by ROC analysis to detect mortality rates. The cut-off value was determined as $10 \mu \mathrm{mol} \cdot \mathrm{L}^{-1}$ for NOx concentration, giving a sensitivity of $55.8 \%$ and a specificity of $80.8 \%$. NOx level (AUC 0.76 ; 95\% CI $0.62-0.90$ ) was numerically superior to cardiac output (AUC 0.64; 95\% CI 0.47-0.82), BNP (AUC 0.59\%; 95\% CI 0.43-0.75), mPAP (AUC 0.53; 95\% CI 0.35-0.71) and PVR (AUC 0.60; 95\% CI 0.39-0.77) (figure 4a). 

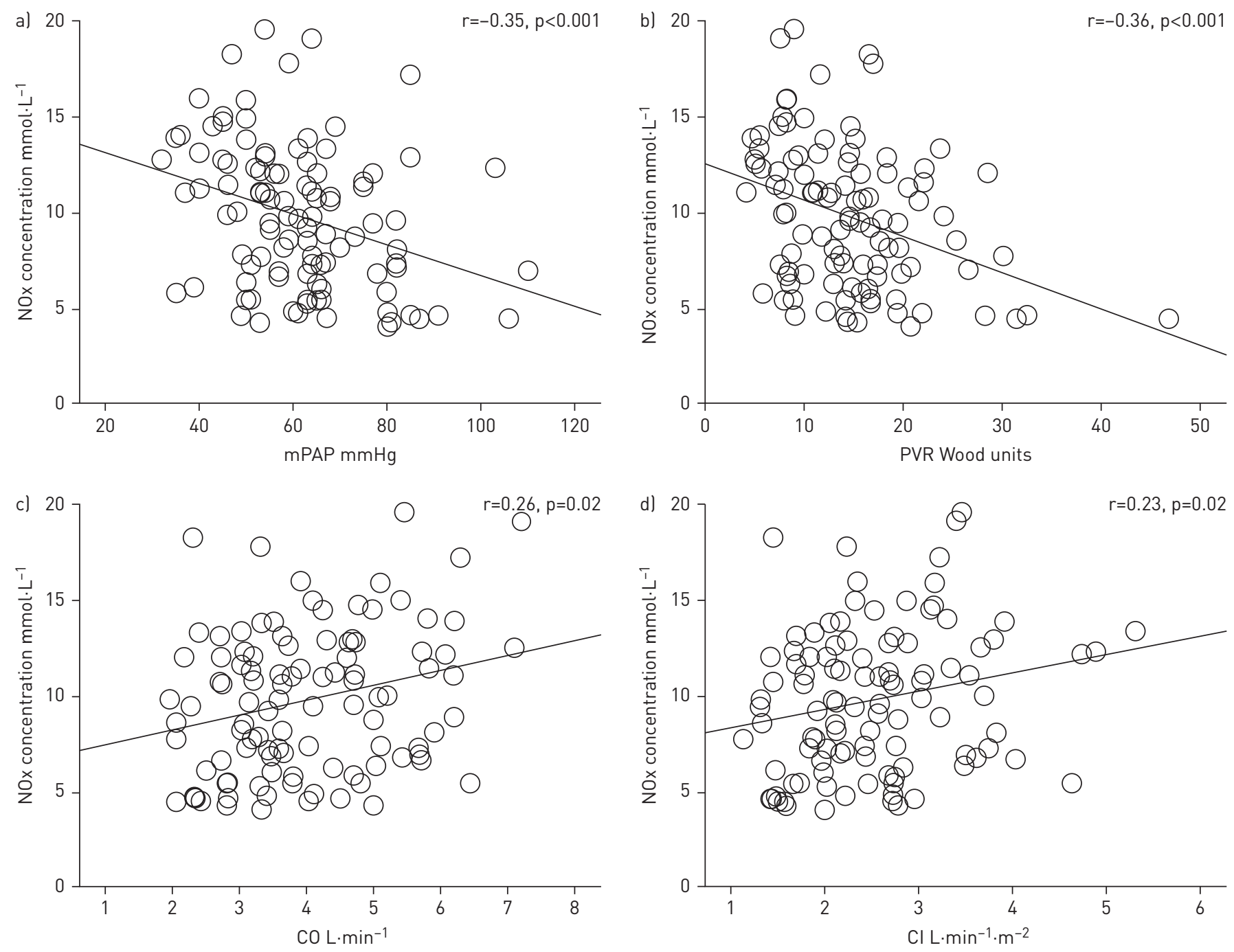

FIGURE 2 Relationship between nitric oxide metabolite (NOx) concentrations with a) mean pulmonary arterial pressure (mPAP), b) pulmonary vascular resistance (PVR), c) cardiac output (CO), and d) cardiac index (CI) in patients with idiopathic pulmonary arterial hypertension.

In 56 patients with a NOx concentration of $\leqslant 10 \mu \mathrm{mol} \cdot \mathrm{L}^{-1}, 21(37.5 \%)$ patients died, whereas only five $(10.4 \%)$ of the 48 patients in $\mathrm{NOx}$ concentrations of $>10 \mu \mathrm{mol} \cdot \mathrm{L}^{-1}$ died $(\mathrm{p}=0.001)$. A comparison with patients with plasma $\mathrm{NOx}$ concentration of $\leqslant 10 \mu \mathrm{mol} \cdot \mathrm{L}^{-1}$, those with $\mathrm{NOx}$ concentrations of $>10 \mu \mathrm{mol} \cdot \mathrm{L}^{-1}$ had significantly lower mPAP and PVR in pulmonary haemodynamics (table 2). Moreover, the proportion of patients carrying a $B M P R 2$ mut with a NOx-concentration of $\leqslant 10 \mu \mathrm{mol} \cdot \mathrm{L}^{-1}$ was greater than for those with a NOx concentration of $>10 \mu \mathrm{mol} \cdot \mathrm{L}^{-1}$ (table 2). Survival was significantly better for

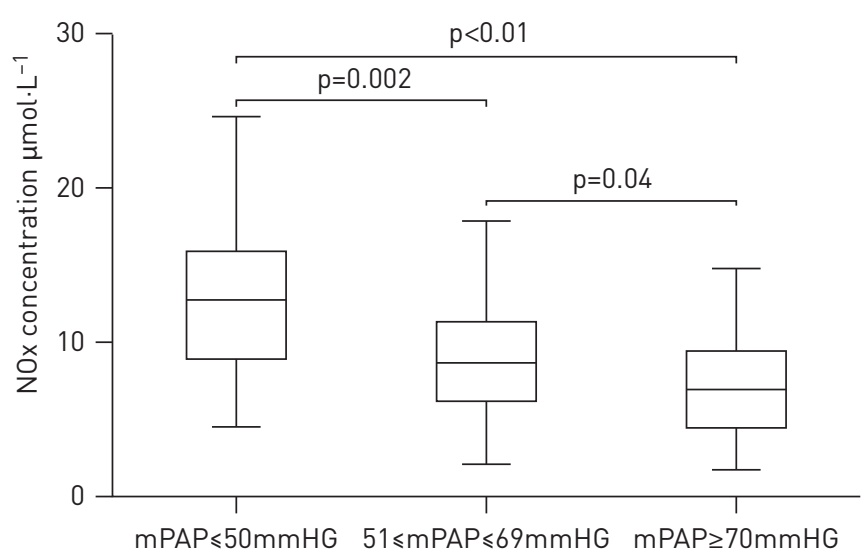

FIGURE 3 Plasma nitric oxide metabolite (NOx) levels in patients with idiopathic pulmonary arterial hypertension between the different mean pulmonary arterial pressure (mPAP) groups. 

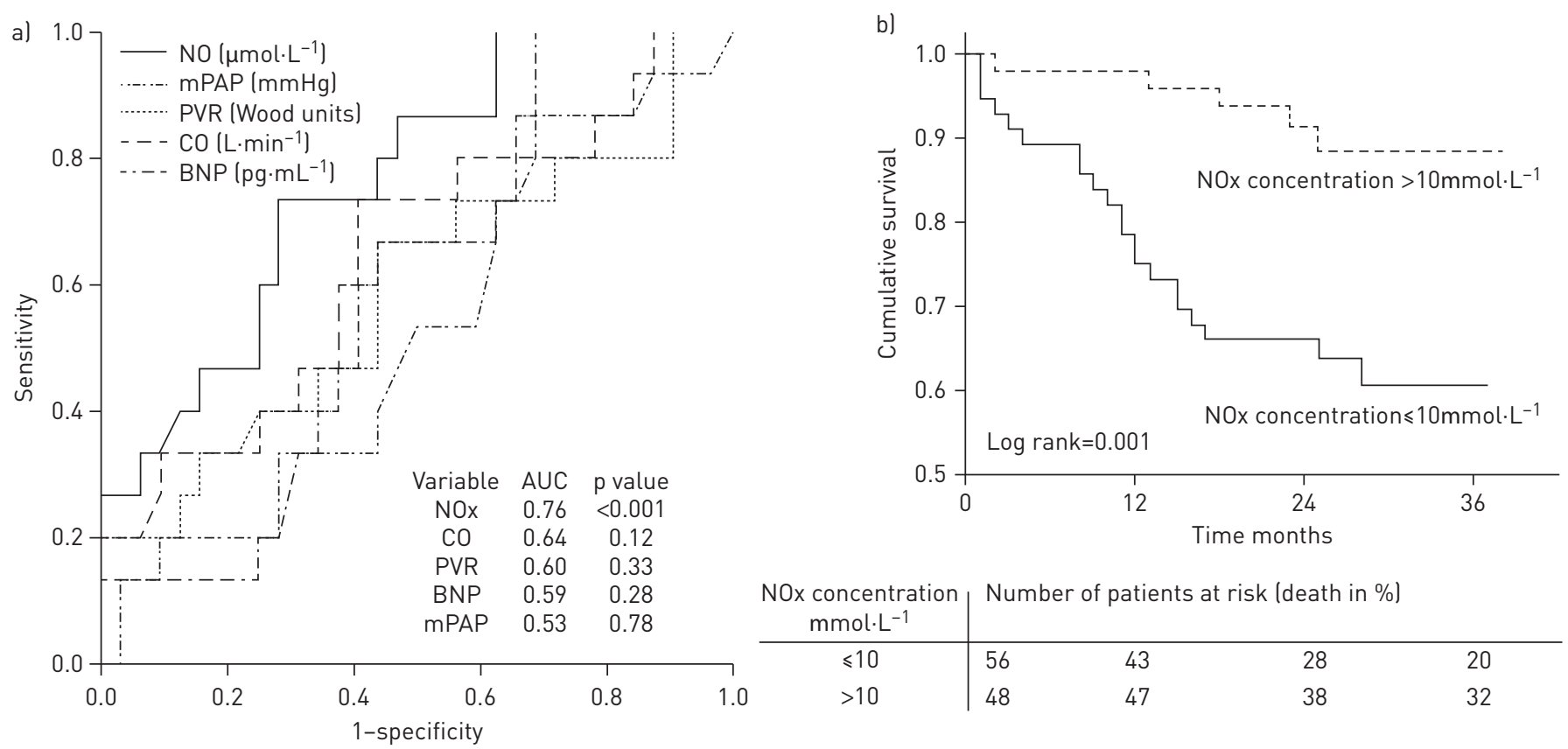

FIGURE 4 Nitric oxide metabolite (NOx) concentration in relation to other markers for an adverse prognosis according to a) receiver operation characteristic (ROC) analyses and b) Kaplan-Meier survival curves for the baseline cut-off plasma NOx concentration in patients with idiopathic pulmonary arterial hypertension. NO: nitric oxide: CO: cardiac output; PVR: pulmonary vascular resistance; BNP: brain natriuretic peptide; mPAP: mean pulmonary arterial pressure.

patients with a NOx concentrations of $>10 \mu \mathrm{mol} \cdot \mathrm{L}^{-1}$ (figure $4 \mathrm{~b}$ ). The 1- and 3-year survival estimates were $75 \%$ and $61 \%$, respectively, for patients with a NOx concentration of $\leqslant 10 \mu \mathrm{mol} \cdot \mathrm{L}^{-1}$, and were $96 \%$ and $88 \%$, respectively, for patients with a NOx concentrations of $>10 \mu \mathrm{mol} \cdot \mathrm{L}^{-1}$ (log-rank test $\mathrm{p}=0.001$ ).

TABLE 2 Baseline characteristics of the study population in relation to NOx

\begin{tabular}{|c|c|c|c|}
\hline & $\mathrm{N} 0 \mathrm{x} \leqslant 10 \mu \mathrm{mol} \cdot \mathrm{L}^{-1}$ & $\mathrm{NOx}>10 \mu \mathrm{mol} \cdot \mathrm{L}^{-1}$ & p-value ${ }^{\#}$ \\
\hline Patients n & 56 & 48 & \\
\hline Age years & $38(27-45)$ & $44(22-51)$ & 0.73 \\
\hline Female & $15(70)$ & 37 (77) & $<0.001$ \\
\hline BMPR2 mutation & $15(27)$ & $4(9)$ & 0.02 \\
\hline BMI $\mathbf{k g} \cdot \mathrm{m}^{-2}$ & $21(19-23)$ & $22(20-26)$ & 0.17 \\
\hline WHO FC & & & 0.78 \\
\hline Class II & $16(29)$ & $16(33)$ & \\
\hline Class III & $33(59)$ & $25(52)$ & \\
\hline Class IV & $7(13)$ & $7(15)$ & \\
\hline Onset to diagnosis months & $24(6-48)$ & $23(8-65)$ & 0.65 \\
\hline 6MWD m & $383(315-425)$ & $423(290-445)$ & 0.47 \\
\hline $\mathrm{BNP} \mathrm{pg} \cdot \mathrm{mL}^{-1}$ & $226(44-435)$ & $116(20-341)$ & 0.70 \\
\hline \multicolumn{4}{|l|}{ Haemodynamic variables } \\
\hline Heart rate bpm & $86(76-95)$ & 84 (72-92) & 0.47 \\
\hline mRAP mmHg & $7(4-11)$ & $8(6-14)$ & 0.69 \\
\hline $\mathrm{mPAP} \mathrm{mmHg}$ & $63(53-67)$ & $61(45-69)$ & 0.002 \\
\hline PAWP mmHg & $9(8-11)$ & $9(6-10)$ & 0.26 \\
\hline $\mathrm{COL} \cdot \mathrm{min}^{-1}$ & $3.9(3.3-5.0)$ & $4.2(3.2-4.8)$ & 0.09 \\
\hline $\mathrm{Cl} \mathrm{L} \cdot \mathrm{min}^{-1} \cdot \mathrm{m}^{-2}$ & $2.4(1.9-3.1)$ & $2.7(2.2-3.2)$ & 0.07 \\
\hline PVR Wood units & $14(9-19)$ & $12(8-17)$ & 0.002 \\
\hline $\mathrm{SvO}_{2} \%$ & $61(55-67)$ & 63 (51-73) & 0.18 \\
\hline \multicolumn{4}{|c|}{ 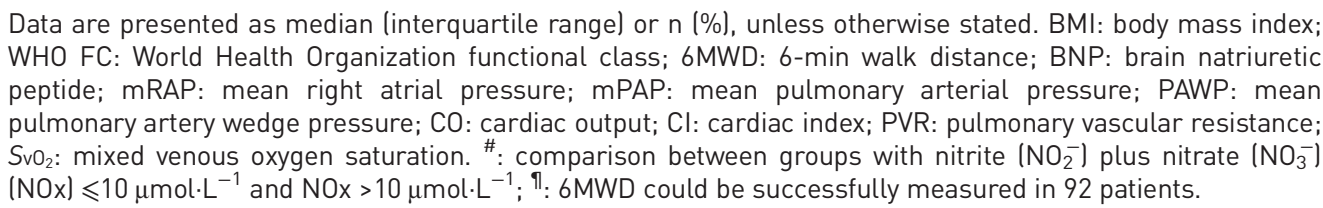 } \\
\hline
\end{tabular}


NOx level in relation to other markers of adverse outcomes

NOx level was significantly associated with the risk of death (table 3). A lower NOx concentration $\left(\leqslant 10 \mu \mathrm{mol} \cdot \mathrm{L}^{-1}\right)$ was associated with higher all-cause mortality after adjustment for age and sex $(\mathrm{p}=0.001)$. This association persisted after the addition with BMPR2mut $(\mathrm{p}=0.002)$. Further adjustment for haemodynamic variables (i.e. mPAP, PVR and cardiac output), a NOx concentration below this cut-off value still maintained a 2.27 -fold increased risk of mortality $(\mathrm{p}=0.003)$. In all models, patients in the lower NOx concentration had almost 2-3-times the risk of mortality compared with those in the higher tertile. Additional adjustment for WHO functional class, $6 \mathrm{MWD}$ and other covariates did not change these results.

\section{Discussion}

As an endothelium-derived relaxing factor, NO represents an important signalling molecule involved in the regulation of basal vasomotor tone and in pathological remodelling of the pulmonary vasculature during the development of PAH [25]. An understanding of NO-related pathway has led to the rapid clinical development of medications to treat PAH. However, it is unclear whether abnormality of NO metabolism is associated with haemodynamic dysfunction and poor outcomes of patients with IPAH. Our results demonstrate that 1) plasma NOx levels were markedly more reduced in patients with IPAH than in healthy subjects, especially for patients that had a BMPR2 mutation; 2) NOx levels correlated with haemodynamic abnormalities; and 3) lower NOx levels were associated with greater mortality risk, suggesting their possible use as prognostic indicators and for possible therapeutic manipulation.

In our study, plasma NOx concentrations were lower in patients with BMPR2mut than those with BMPR2wt. GANGOPAHYAY et al. [16] indicated that stimulation of pulmonary arterial endothelial cells taken from PAH patients with BMPR2 mutations led to decreased eNOS phosphorylation and activity. Loss of $B M P R 2$ may partially disrupt a larger complex of proteins that interact with eNOS, leading to inefficient or impaired signalling $[4,26]$. Among 18\% BMPR2mut patients in our present study, NOx concentration was markedly lower: this was possibly because of reduced compliance of the pulmonary vascular bed. Previous studies have shown that patients with PAH who carry a BMPR2 mutation have a worse prognosis than non-carriers [27-29]. The decreased levels of NO in those with mutant BMPR2 may explain their association with the development of PAH [30]. Although $\mathrm{NO}$ do affect the systemic circulation and can produce systemic hypotension, they are considered "selective" pulmonary vasodialtors $[4,5]$. Herein, the decreased bioavailability and responsiveness to $\mathrm{NO}$ during PAH may occur secondarily to the impaired NO formation or the increased NO consumption.

NO metabolites can be readily detected and quantified. The major pathway of NO metabolism is its stepwise oxidation to nitrite $\left(\mathrm{NO}_{2}^{-}\right)$and nitrate $\left(\mathrm{NO}_{3}^{-}\right)$. In plasma or other physiological fluids or buffers, $\mathrm{NO}$ is oxidised almost completely to nitrite, where it remains stable. KAMEZAKI et al. [12] implied that plasma NOx levels, a marker of systemic NO production, was correlated with the prevalence and severity of electrocardiographically determined left ventricular hypertrophy. The ability of NOx levels to predict long-term outcomes in patients with IPAH is of interesting. Our study showed that risk prediction using NOx concentration appears to be robust, even after adjustments for clinical characteristics, BMPR2mut and haemodynamics. The cut-off level for NOx suggests more IPAH patients may be identified as being at risk using this biomarker. Although plasma BNP levels are recommended for initial risk stratification and are biomarkers for PAH prognoses [31], NOx was superior to BNP in predicting outcomes in our study. NOx may provide an insight into a distinct pathophysiologic process, suggesting that multi-marker strategies can be increasingly used to assess risks and to utilise individual therapies [32].

Total $\mathrm{NO}\left(\mathrm{NO}_{2}^{-} / \mathrm{NO}_{3}^{-}\right)$is found in the plasma of healthy individuals at concentrations ranging between 20 and $40 \mu \mathrm{M}$ under fasting conditions [33]. Nitrite has been proposed as a therapy for pulmonary hypertension based

TABLE 3 Cox proportional hazard analysis for NOx concentration on mortality

\begin{tabular}{lcc} 
Analysis & HR $(95 \%$ Cl) & p value \\
\hline Univariate analyses $^{\#}$ & $2.79(1.68-5.91)$ & 0.001 \\
Multivariate analyses $^{\#}$ & & \\
Model 1 & $3.15(1.51-6.25)$ & 0.001 \\
Model 2+ & $2.21(1.83-5.87)$ & 0.002 \\
Model 3§ & $2.27(1.85-6.02)$ & 0.003 \\
\hline
\end{tabular}

\#: nitrite $\left(\mathrm{NO}_{2}^{-}\right)$plus nitrate $\left(\mathrm{NO}_{3}^{-}\right)(\mathrm{NOx})$ concentrations were dichotomised at $10 \mu \mathrm{mol} \cdot \mathrm{L}^{-1}$; ${ }^{\text {I}}$ : adjusted for age and sex; ${ }^{+}$: model 1 plus BMPR2 mutation; $\S_{\text {: }}$ model 2 plus mean pulmonary arterial pressure, pulmonary vascular resistance and cardiac output. 
on inhalation studies performed on newborn sheep with hypoxia- and thromboxane-induced pulmonary hypertension [34]. Inhale low-dose nebulised sodium nitrite prevented and reversed experimental PAH and heart failure in a chronic hypoxia mouse model and a monocrotaline rat model [10, 35]. Of note, the $\mathrm{NO}_{3}^{-}-\mathrm{NO}_{2}^{-}-\mathrm{NO}$ pathway has been proposed to act as a "back-up" system for $\mathrm{NO}$ generation in situations where conventional pathways for NO synthesis may be compromised [33, 36]. BALIGA et al. [37] have demonstrated that dietary nitrate elicit pulmonary dilation, prevented pulmonary vascular remodelling and reduced right ventricular hypertrophy, which is characteristic of pulmonary hypertension. Thus, there exists an alternative reductive pathway that may aid the therapeutic treatment of $\mathrm{PAH}$.

There was a close correlation between NOx levels and haemodynamic impairment in our study population despite the statistical r-values being weak. This implies that the levels of NOx reflected the degree of endothelial cell apoptosis or obliterative vascular remodelling. Most patients with IPAH, and particularly IPAH patients with a BMPR2 mutation, have little to no pulmonary vasodilator response to NO and only a modest response to PDE5i or sGC stimulators [38]. Some studies have reported elevated NOx levels in patients with pulmonary hypertension. These findings differ from our study and may be due to the type of pulmonary hypertension studied, the age of the patient and body fluid where NOx was measured [39-43]. For example, adult and children patients with associated congenital heart disease have increased plasma nitrate or nitrite levels. It should be noted that endothelia can respond to raised intravascular or cardiac pressure with increased NO production. When pulmonary arterial pressure is raised, enhanced NO production probably acts as a compensatory mechanism in the cardio-haemodynamics of congenital heart disease by decreasing myocardial contractility and causing vascular dilatation. However, nitrate concentrations can be reduced dramatically after cardiac surgery and also in older children. Despite these discrepancies regarding NOx values in pulmonary hypertension, interest in plasma NOx in pulmonary hypertension is growing, as this marker may relate to the degree of pulmonary hypertension, and could be used to monitor response to a specific therapy.

As one of the body's most versatile molecules, NO scavenging by reactive oxygen species (ROS) is normally controlled through the well-balanced production of NO and ROS [4,44]. In this chronic pulmonary hypertension model, upstream dysregulation of ROS/NO redox homeostasis impairs vascular tone and contributes to cell proliferation and obliteration of the vasculature. Canonical ROS and NO signalling pathways are simultaneously disrupted in PAH. Thereby, selective inhibitors of cGMP-specific PDE-5 may have direct and indirect effects on PAH by preventing hydrolysis of cGMP and ROS [4, 45]. In addition, the stimulators that directly activate sGC in a preferential manner do not require NO for this activation. The approval of riociguat as a potential agent for $\mathrm{PAH}$ treatment acts on exciting the enzyme and elevating sensitivity to lower levels of $\mathrm{NO}[6,46]$. However, whether treatment with sGC stimulator reverses PAH through reduction of ROS formation or increase NO bioavailability is unclear. Thus, a stratagem to increase bioavailable NO if there is endothelial dysfunction and reduced endogenous NO production could be expected to have a favourable effect [47].

\section{Study limitations}

There are several limitations to our study. Firstly, plasma NOx levels were only measured at the baseline time point; we were unable to test the variability and prognostic changes over time or the impact of different therapies. It remains to be elucidated whether the outcomes of this study are relevant to the selected population. Secondly, although blood sample taken to measure plasma NOx levels were collected in the morning (07:00-09:00 h) after an overnight fast $(>12 \mathrm{~h})$, the optimal time to collect these samples remains unclear. Further studies are needed to clarify this issue. Finally, we may have underestimated NOx concentration compared with the corresponding concentrations measured by high performance liquid chromatography Griess method. However, enzyme immunoassay techniques offer ease of performance and are also available to measure NOx [48]. Differences in our study between inter-batch and inter-operator variability were reasonable in our study. Therefore, the choice of analytical method needs to consider technical familiarity, cost and personal preference. Furthermore, another potential limitation is lack of exact match between control subjects and patients although the present results are promising.

\section{Conclusions}

In conclusion, we have demonstrated that plasma NOx levels were markedly lower in patients with IPAH compared with healthy controls, when correlated against haemodynamic measures of diseases severity and presence of the BMPR2 mutation. Patients with reduced NOx levels had an increased risk for mortality independently of clinical characteristics and other risk factors. Our findings add further evidence to the concept that NO production may be reduced in patients with IPAH, and highlight the importance of NO in the pathogenesis of PAH. In addition, the development of effective therapeutic strategies using NOx metabolites requires further study and clarification. 


\section{Acknowledgements}

The authors gratefully acknowledge the contribution of all investigators who participated in this study. We also thank the patients who participated in the study.

Part of this study (<300 words) was accepted by the American Thoracic Society (ATS) as an oral presentation at their 2015 International Conference and was awarded an Abstract Scholarship by the ATS and Pulmonary Hypertension Association at Denver, Colorado.

\section{References}

1 Voelkel NFTR, Tuder R, Weir EK. Pathophysiology of primary pulmonary hypertension: from physiology to molecular mechanisms. In: Rubin LRS, ed., Primary pulmonary hypertension. New York, Marcel Dekker, 1997; pp. 83-130.

2 Humbert M, Sitbon O, Simonneau G. Treatment of pulmonary arterial hypertension. N Engl J Med 2004; 351 : $1425-1436$.

3 Morrell NW, Adnot S, Archer SL, et al. Cellular and molecular basis of pulmonary arterial hypertension. $J$ Am Coll Cardiol 2009; 54: S20-S31.

4 Tabima DM, Frizzell S, Gladwin MT. Reactive oxygen and nitrogen species in pulmonary hypertension. Free Radic Biol Med 2012; 52: 1970-1986.

5 Galie N, Corris PA, Frost A, et al. Updated treatment algorithm of pulmonary arterial hypertension. J Am Coll Cardiol 2013; 62: D60-D72.

6 Rubin LJ, Galiè N, Grimminger F, et al. Riociguat for the treatment of pulmonary arterial hypertension: a long-term extension study (PATENT-2). Eur Respir J 2015; 45: 1303-1313.

7 Pullamsetti S, Kiss L, Ghofrani HA, et al. Increased levels and reduced catabolism of asymmetric and symmetric dimethylarginines in pulmonary hypertension. Faseb J 2005; 19: 1175-1177.

8 Nakata S, Tsutsui M, Shimokawa H, et al. Spontaneous myocardial infarction in mice lacking all nitric oxide synthase isoforms. Circulation 2008; 117: 2211-2223.

9 Nagaya $\mathrm{N}$, Uematsu M, Oya $\mathrm{H}$, et al. Short-term oral administration of L-arginine improves hemodynamics and exercise capacity in patients with precapillary pulmonary hypertension. Am J Respir Crit Care Med 2001; 163: 887-891.

10 Bueno M, Wang J, Mora AL, et al. Nitrite signaling in pulmonary hypertension: mechanisms of bioactivation, signaling, and therapeutics. Antioxid Redox Signal 2013; 18: 1797-1809.

11 Bryan NS, Grisham MB. Methods to detect nitric oxide and its metabolites in biological samples. Free Radic Biol Med 2007; 43: 645-657.

12 Kamezaki F, Tsutsui M, Takahashi M, et al. Plasma levels of nitric oxide metabolites are markedly reduced in normotensive men with electrocardiographically determined left ventricular hypertrophy. Hypertension 2014; 64: $516-522$.

13 Hol JW, van Lier F, Valk M, et al. Effect of major and minor surgery on plasma levels of arginine, citrulline, nitric oxide metabolites, and ornithine in humans. Ann Surg 2013; 258: 1072-1078.

14 Fan YF, Zhang R, Jiang X, et al. The phosphodiesterase-5 inhibitor vardenafil reduces oxidative stress while reversing pulmonary arterial hypertension. Cardiovasc Res 2013; 99: 395-403.

15 Machado RD, Eickelberg O, Elliott CG, et al. Genetics and genomics of pulmonary arterial hypertension. $J$ Am Coll Cardiol 2009; 54: S32-S42.

16 Gangopahyay A, Oran M, Bauer EM, et al. Bone morphogenetic protein receptor II is a novel mediator of endothelial nitric-oxide synthase activation. J Biol Chem 2011; 286: 33134-33140.

17 Simonneau G, Robbins IM, Beghetti M, et al. Updated clinical classification of pulmonary hypertension. J Am Coll Cardiol 2009; 54: S43-S54.

18 Galiè N, Humbert M, Vachiery JL, et al. 2015 ESC/ERS Guidelines for the diagnosis and treatment of pulmonary hypertension. Eur Respir J 2015; 46: 903-975.

19 Node K, Kitakaze M, Yoshikawa H, et al. Reversible reduction in plasma concentration of nitric oxide induced by cigarette smoking in young adults. Am J Cardiol 1997; 79: 1538-1541.

20 Ott C, Schlaich MP, Schmidt BM, et al. Rosuvastatin improves basal nitric oxide activity of the renal vasculature in patients with hypercholesterolemia. Atherosclerosis 2008; 196: 704-711.

21 Serebruany V, Sani Y, Eisert C, et al. Effects of aggrenox and aspirin on plasma endothelial nitric oxide synthase and oxidised low-density lipoproteins in patients after ischaemic stroke. The aggrenox versus aspirin therapy evaluation (AGATE) biomarker substudy. Thromb Haemost 2011; 105: 81-87.

22 Zhang R, Jing ZC. Isoprostane as a promising biomarker in pulmonary arterial hypertension: Preanalytical and analytical viewpoints. Response to letter to the editor. Int J Cardiol 2014; 177: 632-633.

23 Zhang R, Sun ML, Fan YF, et al. Plasma 15-f2t-isoprostane in idiopathic pulmonary arterial hypertension. Int J Cardiol 2014; 175: 268-273.

24 Mitsuhashi $\mathrm{H}$, Yatsuya $\mathrm{H}$, Tamakoshi $\mathrm{K}$, et al. Adiponectin level and left ventricular hypertrophy in Japanese men. Hypertension 2007; 49: 1448-1454.

25 Chatterjee A, Black SM, Catravas JD. Endothelial nitric oxide (NO) and its pathophysiologic regulation. Vascul Pharmacol 2008; 49: 134-140.

26 Giaid A, Saleh D. Reduced expression of endothelial nitric oxide synthase in the lungs of patients with pulmonary hypertension. N Engl J Med 1995; 333: 214-221.

27 Elliott CG, Glissmeyer EW, Havlena GT, et al. Relationship of BMPR2 mutations to vasoreactivity in pulmonary arterial hypertension. Circulation 2006; 113: 2509-2515.

28 Sztrymf B, Coulet F, Girerd B, et al. Clinical outcomes of pulmonary arterial hypertension in carriers of BMPR2 mutation. Am J Respir Crit Care Med 2008; 177: 1377-1383.

29 Evans JD, Girerd B, Montani D, et al. BMPR2 mutations and survival in pulmonary arterial hypertension: an individual participant data meta-analysis. Lancet Respir Med 2016; 4: 129-137.

30 Wang H, Ji R, Meng J, et al. Functional changes in pulmonary arterial endothelial cells associated with BMPR2 mutations. PloS One 2014; 9: e106703. 
31 Nagaya N, Nishikimi T, Uematsu M, et al. Plasma brain natriuretic peptide as a prognostic indicator in patients with primary pulmonary hypertension. Circulation 2000; 102: 865-870.

32 Nickel $\mathrm{N}$, Kempf $\mathrm{T}$, Tapken $\mathrm{H}$, et al. Growth differentiation factor-15 in idiopathic pulmonary arterial hypertension. Am J Respir Crit Care Med 2008; 178: 534-541.

33 Kapil V, Weitzberg E, Lundberg JO, et al. Clinical evidence demonstrating the utility of inorganic nitrate in cardiovascular health. Nitric Oxide 2014; 38: 45-57.

34 Hunter CJ, Dejam A, Blood AB, et al. Inhaled nebulized nitrite is a hypoxia-sensitive NO-dependent selective pulmonary vasodilator. Nat Med 2004; 10: 1122-1127.

35 Zuckerbraun BS, Shiva S, Ifedigbo E, et al. Nitrite potently inhibits hypoxic and inflammatory pulmonary arterial hypertension and smooth muscle proliferation via xanthine oxidoreductase-dependent nitric oxide generation. Circulation 2010; 121: 98-109.

36 Lundberg JO, Weitzberg E, Gladwin MT. The nitrate-nitrite-nitric oxide pathway in physiology and therapeutics. Nat Rev Drug Discov 2008; 7: 156-167.

37 Baliga RS, Milsom AB, Ghosh SM, et al. Dietary nitrate ameliorates pulmonary hypertension: cytoprotective role for endothelial nitric oxide synthase and xanthine oxidoreductase. Circulation 2012; 125: 2922-2932.

38 Liu D, Wu WH, Mao YM, et al. BMPR2 mutations influence phenotype more obviously in male patients with pulmonary arterial hypertension. Circ Cardiovasc Genet 2012; 5: 511-518.

39 Malinovschi A, Henrohn D, Eriksson A, et al. Increased plasma and salivary nitrite and decreased bronchial contribution to exhaled NO in pulmonary arterial hypertension. Eur J Clin Invest 2011; 41: 889-897.

40 Sungur M, Ocal B, Oğuz D, et al. Plasma endothelin-1 and nitrate levels in Down's syndrome with complete atrioventricular septal defect-associated pulmonary hypertension: a comparison with non-Down's syndrome children. Eur J Pediatr 2009; 168: 593-597.

41 Ikemoto Y, Teraguchi M, Kobayashi Y. Plasma levels of nitrate in congenital heart disease: comparison with healthy children. Pediatr Cardiol 2002; 23: 132-136.

42 Takaya J, Teraguchi M, Nogi S, et al. Relation between plasma nitrate and mean pulmonary arterial pressure in ventricular septal defect. Arch Dis Child 1998; 79: 498-501.

43 Gorenflo M, Zheng C, Pöge A, et al. Metabolites of the L-arginine-NO pathway in patients with left-to-right shunt. Clin Lab 2001; 47: 441-447.

44 Nisbet RE, Bland JM, Kleinhenz DJ, et al. Rosiglitazone attenuates chronic hypoxia-induced pulmonary hypertension in a mouse model. Am J Respir Cell Mol Biol 2010; 42: 482-490.

45 Hemnes AR, Zaiman A, Champion HC. PDE5A inhibition attenuates bleomycin-induced pulmonary fibrosis and pulmonary hypertension through inhibition of ROS generation and RhoA/Rho kinase activation. Am J Physiol Lung Cell Mol Physiol 2008; 294: L24-L33.

46 Ghofrani HA, Galie N, Grimminger F, et al. Riociguat for the treatment of pulmonary arterial hypertension. N Engl J Med 2013; 369: 330-340.

47 Papapetropoulos A, Hobbs AJ, Topouzis S. Extending the translational potential of targeting NO/cGMP-regulated pathways in the CVS. Br J Pharmacol 2015; 172: 1397-1414.

48 Bryan NS, Grisham MB. Methods to detect nitric oxide and its metabolites in biological samples. Free Radic Biol Med 2007; 43: 645-657. 